\title{
Influência da Moagem da Cinza do Bagaço de Ca- na-de-açúcar na Atividade Pozolânica
}

\author{
Title: Influence of milling of sugarcane bagasse ash in the pozzolanic activity \\ Jofre Silva Lima \\ Escola Politécnica de Pernambuco \\ Eliana Cristina Barreto Monteiro \\ Universidade de Pernambuco \\ Escola Politécnica de Pernambuco \\ 50.720-001 - Recife, Brasil \\ jofresl@gmail.com \\ Universidade de Pernambuco \\ 50.720-001 - Recife, Brasil \\ eliana@poli.br
}

\begin{abstract}
Resumo Este trabalho tem como objetivo verificar a influência da moagem da cinza do bagaço de canade-açúcar (CBCA) na atividade pozolânica mensurada através do índice de atividade com a cal (IAC), de acordo com a norma brasileira NBR 5751 (2015). A cinza do bagaço de cana-deaçúcar é um resíduo importante da região nordeste e do Estado de Pernambuco, porém o seu descarte ainda é um problema. Foi utilizada a cinza oriunda do processo de produção de álcool de uma usina localizada no Estado de Pernambuco. A cinza foi retirada diretamente da caldeira na qual o bagaço da cana foi queimado. As frações retidas nas peneiras abaixo de 2,4cm foram utilizada para moagem. O estudo foi realizado com a cinza sem moer e com três diferentes graus de moagem (com áreas específicas de 300, 400 e $500 \mathrm{~m}^{2} / \mathrm{kg}$ ) em comparação com o metacaulim. A análise da atividade pozolânica foi realizada de acordo com a NBR 5751 (2015), a qual descreve o método para determinação de atividade pozolânica com a cal. De acordo com os resultados obtidos, a CBCA utilizada neste estudo não atingiu o IAC mínimo de 6 Mpa para ser classificada como material pozolânico. No entanto, percebeu-se que a CBCA moída apresentou resultados de IAC superiores à CBCA sem moagem, sendo a relação direta entre moagem (superficie específica) e IAC.
\end{abstract}

Palavras-Chave: Cinza do bagaço de cana-de-açúcar, Atividade pozolânica, moagem

\begin{abstract}
The purpose of this work is verifying the influence of milling of sugar cane bagasse ash (SCBA) in the pozzolanic activity with lime (IAC), according to Brazilian standard NBR 5751. The SCBA is an important residue of the northeast region and the State of Pernambuco, however their disposal still a problem. The ash used is coming from ethanol production process of a plant located in the State of Pernambuco. The ash was taken directly from the boiler in which the sugar cane bagasse was burned. The fractions retained on the sieve below $2.4 \mathrm{~cm}$ were used for milling. This study was carried out with the unmilled ash, three different degrees of milling (with specific surface areas: 300,400 and $500 \mathrm{~m}^{2} / \mathrm{kg}$ ) and metakaolin as reference. Analysis of pozzolanic activity was performed according to NBR 5751, which describes the method for determining the pozzolanic activity index with hydrated lime. The results indicate that the SCBA IAC index did not reached at least 6 MPa to qualify as a pozzolanic material. However, the milled SCBA showed IAC results higher than the unmilled SCBA, and milling (specific surface area) and IAC show direct relationship.
\end{abstract}

Keywords: Sugarcane bagasse ash, Pozzolanic activity, milling 


\section{Introdução}

O Brasil é responsável por mais da metade do açúcar comercializado no mundo, sendo responsável pela moagem de mais de 632 milhões de toneladas de cana-deaçúcar na safra 2014/2015. Para cada tonelada de cana é gerado mais de seis quilos de um resíduo composto em sua maioria por sílica. Este resíduo é a cinza do bagaço da cana-de-açúcar.

Pesquisas indicam que esta cinza poderia ter propriedades pozolânicas e ser utilizada como substituição parcial do cimento. Sendo uma alternativa sustentável por retirar este resíduo da natureza e atuar na diminuição do consumo de dióxido de carbono e de recursos naturais inerentes ao processo de produção do cimento.

As pozolanas são materiais conhecidos por elevar a durabilidade do concreto, combatendo muitos agentes agressivos. Sendo assim, caso a cinza apresente atividade pozolânica, poderia atuar na diminuição de patologias normalmente encontradas em obras civis.

\section{Fundamentação Teórica}

\subsection{Materiais Pozolânicos}

Materiais pozolânicos são materiais silicosos ou silicoaluminosos que, sozinhos, possuem pouca ou nenhuma propriedade ligante mas que, quando finamente divididos e na presença da água, reagem com o hidróxido de cálcio à temperatura ambiente, formando compostos com propriedades ligantes.[1]

De acordo com a NBR 12653 [1], as pozolanas podem ser:

a) Classe N: pozolanas naturais e artificiais, como certos materiais vulcânicos de caráter petrográfico ácido, cherts silicosos, terras diatomáceas, argilas calcinadas, materiais provenientes de tratamento térmico e subprodutos industriais;

b) Classe C: cinzas volantes produzidas pela queima de carvão mineral em usinas termoelétricas;

c) Classe E: Quaisquer pozolanas, não contempladas nas classes $\mathrm{N}$ e $\mathrm{C}$.

A adição de pozolanas aos concretos, argamassas e pastas apresenta uma melhoria nas características dos mesmos como o aumento da resistência à compressão e à flexão, a idades avançadas, redução da porosidade e permeabilidade, aumento da resistência a sulfatos, aumento da resistência à difusibilidade de íons cloreto, mitigação da reação álcali-agregado, redução da ocorrência de eflorescências e aumento da resistividade elétrica [1].
Essas características isoladas ou em conjunto fazem da pozolana uma adição que eleva a durabilidade do concreto agindo em muitos agentes agressivos. Sendo assim, apresentaria uma diminuição significativa em patologias normalmente encontradas em edificações, como reação álcali-agregado, fissuras de origem térmica, infiltração, ataques de sulfatos, ataques de cloretos, dentre outras [2].

\subsection{Cinza do Bagaço de Cana-de-Açúcar}

O Brasil é hoje o maior produtor de cana-de-açúcar do mundo, sendo responsável por mais da metade do açúcar comercializado no mundo. Sendo também o maior produtor mundial de açúcar e etanol [3].

Segundo dados da União da Indústria de Cana-deAçúcar (ÚNICA), na safra 2014/2015, o Brasil foi responsável pela moagem de mais de 632 milhões de toneladas de cana-de-açúcar, dos quais Pernambuco foi responsável por quase 15 milhões [4].

Uma tonelada de cana gera aproximadamente $320 \mathrm{~kg}$ de bagaço, dos quais $90 \%$ são utilizados para a geração de energia. Atualmente utiliza-se o bagaço gerado da usina para a produção da energia, tornando a usina autossustentável energeticamente e, em alguns casos, há venda do excedente de energia para distribuidoras. A capacidade de cogeração de energia com o bagaço é de $1650 \mathrm{MW}$ ou $2 \%$ da demanda nacional $[5,6]$.

Para cada $250 \mathrm{~kg}$ de bagaço de cana queimado nas caldeiras, produz-se aproximadamente 6 quilos de cinzas. É gerada então uma grande quantidade de uma cinza pesada (que fica no fundo das caldeiras), composta basicamente de materiais inorgânicos (em sua maioria sílica) e com aspecto grosseiro. Atualmente a cinza do bagaço da cana-de-açúcar (CBCA) está sendo utilizada em atividades pouco nobres, como a fertilização de lavouras, mesmo sabendo-se que pesquisas indicam que a CBCA não apresenta nutrientes minerais adequados para esta finalidade $[7,8,9]$.

A utilização da CBCA em compostos de cimento traria uma contribuição para a sustentabilidade do planeta tanto pelo lado da indústria agrícola, com a destinação de um resíduo gerado em uma das suas principais atividades, quanto pelo lado da construção civil, com a substituição parcial do cimento Portland que é um material com altíssimo nível de emissão de $\mathrm{CO}_{2}$ e grande consumo de fontes naturais inerentes ao seu processo de produção. [10]

Pesquisas já indicam a possível utilização da CBCA na produção de material vitro-cerâmico [11], no melhoramento de materiais cerâmicos [8], na produção de fibrocimento [5], na substituição do agregado miúdo na produção de argamassas [9], na confecção de chapas, substituindo a madeira [12], na produção de matrizes 
ativadas alcalinamente [13] e também na substituição parcial do cimento $[3,5,6,14]$.

Quanto à pozolanicidade da CBCA, os dados encontrados na literatura se mostraram bastante divergentes. Alguns autores concluíram que os índices de atividade pozolânica da CBCA comprovariam a sua pozolanicidade. E que melhoras nas condições de queima (como a queima controlada ou a recalcinação em temperaturas controladas) e moagem (com o aumento da superfície específica) poderiam resultar em significativas melhoras das suas características reativas $[15,16,17,18]$.

Enquanto para outros a cinza apresentaria baixa atividade pozolânica, por encontrar-se na forma de cristais e apresentar baixa área superficial. Mesmo assim, em baixa quantia poderia substituir o cimento sem diminuir a resistência do concreto, funcionando como fíler $[6,19]$.

Contudo parece haver um consenso dos estudos pesquisados de que a adição da CBCA apresenta uma melhora em características de argamassas e concretos.

\section{Objetivos}

Este artigo se propõe a analisar a influência do grau de moagem da cinza do bagaço de cana-de-açúcar. Será avaliado o Índice de Atividade com Cal (IAC), de acordo com a NBR 5751 [20] com a cinza sem moer e com três diferentes graus de moagem em comparação com o metacaulim, pozolana amplamente utilizada na região.

\section{Materiais e Métodos}

\subsection{Materiais}

Foi utilizada a cinza oriunda do processo de produção álcool de uma usina localizada no Estado de Pernambuco. A cinza foi retirada diretamente da caldeira na qual o bagaço de cana-de-açúcar foi queimado. Inicialmente a CBCA foi seca em estufa a $100^{\circ} \mathrm{C}$. Posteriormente, a CBCA foi peneirada na malha de abertura de $2,4 \mathrm{~mm}$ e a fração passante (Figura 1) foi moída até atingir a superfície específica desejada, aferida pelo método de permeabilidade ao ar (Método de Blaine) [21]. Foram utilizados três diferentes graus de moagem, a cinza sem qualquer tipo de moagem e uma pozolana de referência (metacaulim), como mostra a Tabela 1. Na Figura 2 encontra-se a curva granulométrica resultante da cinza antes de qualquer tratamento (CBCA).

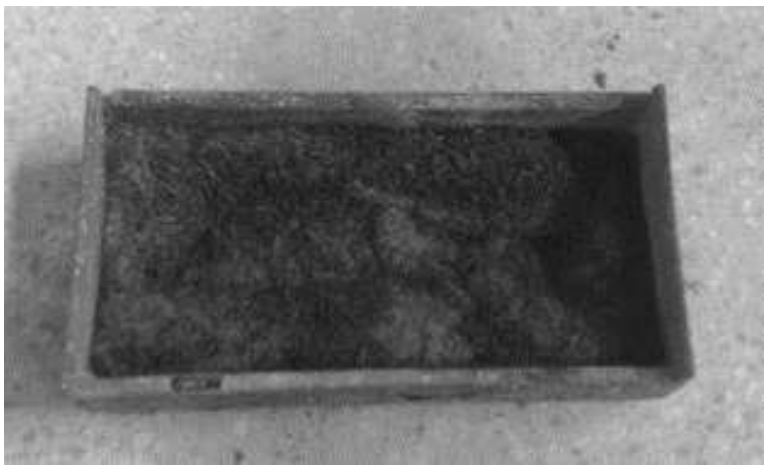

Figura 1: CBCA passante na $\# 2,4 \mathrm{~mm}$

\begin{tabular}{|c|c|}
\hline Material & Descrição \\
\hline CBCAN & $\begin{array}{l}\text { Cinza do bagaço de cana-de-açúcar } \\
\text { "in natura" }\end{array}$ \\
\hline CBCAN3 & $\begin{array}{l}\text { Cinza do bagaço de cana-de-açúcar } \\
\text { "in natura" moída até atingir área } \\
\text { específica igual a } 300 \pm 20 \mathrm{~m}^{2} / \mathrm{Kg}\end{array}$ \\
\hline CBCAN4 & $\begin{array}{l}\text { Cinza do bagaço de cana-de-açúcar } \\
\text { "in natura" moída até atingir área } \\
\text { específica igual a } 400 \pm 20 \mathrm{~m}^{2} / \mathrm{Kg}\end{array}$ \\
\hline CBCAN5 & $\begin{array}{l}\text { Cinza do bagaço de cana-de-açúcar } \\
\text { "in natura" moída até atingir área } \\
\text { específica igual a } 500 \pm 20 \mathrm{~m}^{2} / \mathrm{Kg}\end{array}$ \\
\hline MTC & Metacaulim \\
\hline
\end{tabular}

Tabela 1: Resumo das adições utilizadas

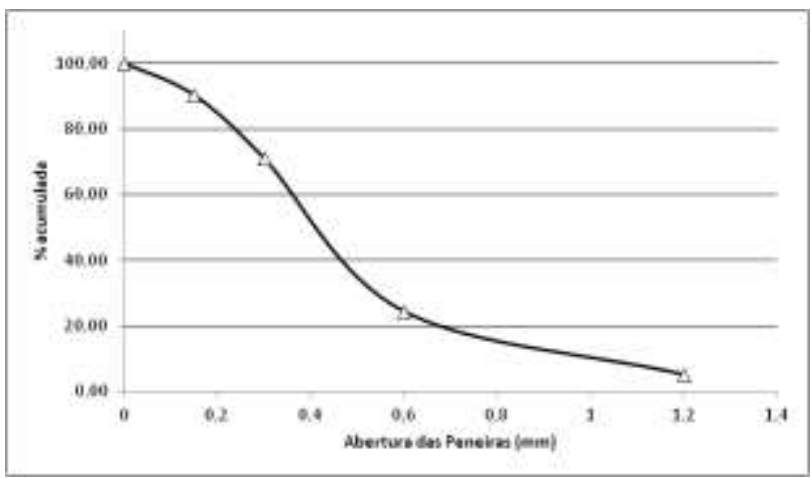

Figura 2: Curva granulométrica da $\mathrm{CBCA}$

Para verificar a influência da moagem na atividade pozolânica foi utilizado o procedimento descrito pela NBR 5751 [20], a qual determina o índice de atividade com cal (IAC). A norma prescreve a preparação de uma argamassa contendo 1 parte de hidróxido de cálcio, 9 partes de areia e uma quantidade de material pozolânico que corresponde ao dobro do volume de hidróxido de cálcio. A quantidade de água é determinada de modo a se 
obter argamassas com índice de consistência (NBR 7215 [22]) de $225 \pm 5 \mathrm{~mm}$. Para a determinação do volume absoluto de material pozolânico a ser utilizado é necessária a determinação da massa específica dos materiais utilizados, a qual foi obtida de acordo com a NBR NM 23 [23]. Os resultados de massa específica e de área específica (NBR NM 76 [21]) são apresentados na Tabela 2.

\begin{tabular}{l|l|l}
\hline Material & $\begin{array}{c}\text { Massa Específica } \\
\left(\mathbf{g} / \mathbf{c m}^{3}\right)\end{array}$ & $\begin{array}{c}\text { Área Específica } \\
\left(\mathbf{m}^{2} / \mathbf{k g}\right)\end{array}$ \\
\hline CBCAN & 2,613 & 71,06 \\
\hline CBCAN3 & 2,613 & 311,60 \\
\hline CBCAN4 & 2,613 & 394,35 \\
\hline CBCAN5 & 2,613 & 508,23 \\
\hline MTC & 2,566 & 2245,49
\end{tabular}

Tabela 2: Massa específica e área específica dos materiais utilizados

Para este estudo foi utilizado um hidróxido de cálcio p.a., conforme indica a NBR 5751 [20], e sua massa específica foi determinada, sendo igual a $2,20 \mathrm{~g} / \mathrm{cm}^{3}$. Para a confecção de todas as argamassas, empregou-se como agregado miúdo uma areia quartzosa que foi lavada, em seguida, seca em estufa a $100^{\circ} \mathrm{C}$ e peneirada na malha de abertura de $4,8 \mathrm{~mm}$. Após esta etapa, a areia foi peneirada e selecionadas as frações $2,4 \mathrm{~mm}-1,2 \mathrm{~mm}, 1,2 \mathrm{~mm}-0,6$ $\mathrm{mm}, 0,6 \mathrm{~mm}-0,3 \mathrm{~mm}$ e $0,3 \mathrm{~mm}-0,15 \mathrm{~mm}$, sendo utilizado $25 \%$ de cada fração para a composição da areia. Este procedimento foi realizado de modo a se assemelhar ao procedimento utilizando areia normal segundo a NBR 7215 [24].

\subsection{Métodos de Ensaio}

Para cada mistura realizada, a norma NBR 5751 [20] determina a confecção de 3 corpos-de-prova cilíndricos $(5 \times 10 \mathrm{~cm})$ que após a moldagem são colocados em cura dentro dos próprios moldes por 24 horas $\left(23 \pm 2^{\circ} \mathrm{C}\right)$. No entanto, optou-se por aumentar o número de corpos-deprova para 6 , com intuito de minimizar possíveis perdas. Em seguida os corpos-de-prova ainda dentro dos moldes são colocados em estufa a $55 \pm 2^{\circ} \mathrm{C}$ por 6 dias. Aos 7 dias de idade, os corpos-de-prova são retirados 4 horas antes do ensaio de compressão e capeados com enxofre. O ensaio de resistência à compressão foi realizado em corpos-de-prova cilíndricos $(5 \times 10 \mathrm{~cm})$ de argamassa de acordo com prescrito pela NBR 7215 [22], sendo utilizada a prensa hidráulica Shimadzu - modelo UH-200A. De acordo com a NBR 7215 [21], foi aplicada uma velocidade de carregamento igual a $0,25 \mathrm{MPa} / \mathrm{s}$. A NBR 5751 [20] determina que o índice de atividade com cal (IAC) é a resistência à compressão média aos 7 dias de idade da argamassa com material pozolânico. De acordo com a NBR 12653 [1], o material é considerado pozolânico quando apresenta um IAC de no mínimo $6 \mathrm{MPa}$.

\section{Materiais e Métodos}

De acordo com a NBR 5751 [20], foram preparadas todas as argamassas com a quantidade de água necessária para obter um índice de consistência de $225 \pm 5 \mathrm{~mm}$ na mesa de consistência. $\mathrm{O}$ índice de consistência consiste da média de dois diâmetros ortogonais obtidos na mesa de consistência. A Tabela 3 apresenta os traços das argamassas obtidos para a confecção de 6 corpos-de-prova e os resultados obtidos na determinação do IAC. Considerou-se que o aglomerante é a soma da massa de hidróxido de cálcio mais a massa do material pozolânico. Observase que nenhuma das argamassas com CBCA conseguiu atingir o IAC mínimo de $6 \mathrm{MPa}$ exigido pela NBR 12653 [1]. No entanto, observa-se que a moagem proporcionou o aumento do IAC quando comparamos a CBCA sem tratamento (CBCAN) e as demais misturas com tratamento. Percebe-se também que o IAC aumenta à medida que aumenta a área específica da cinza. Conforme o esperado o metacaulim apresentou um IAC alto, por se tratar de uma pozolana de alta reatividade.

Os resultados da resistência à compressão aos 7 dias segundo a NBR 5751 [20] são apresentados na Figura 3. Conforme citado anteriormente, observa-se que a CBCA não apresenta IAC para que seja classificada como material pozolânico. De modo geral, percebe-se um crescimento significativo no IAC a medida que se aumenta o grau de moagem da CBCA, indicando que este tratamento se mostra bastante efetivo. Pois é consensual na bibliografia do tema que o aumento da superfície específica do material é fundamental para a melhora do seu potencial pozolânico. Em trabalhos futuros deve-se analisar outros graus de moagem, que apresentem uma área específica superior àquelas encontradas nas cinzas estudadas.

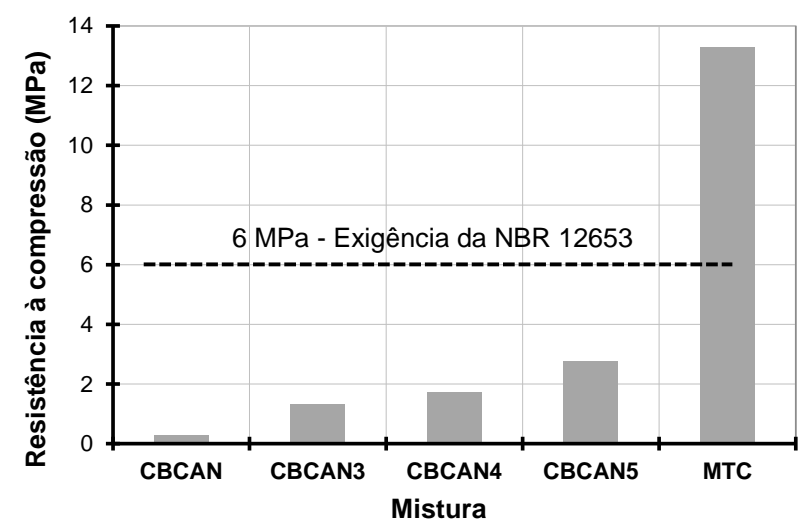

Figura 3: Efeito da moagem na resistência à compressão aos 7 dias segundo a NBR 5751 
Revista de Engenharia e Pesquisa Aplicada (2016) 1-1:23-28

\begin{tabular}{|c|c|c|c|c|c|c|c|c|}
\hline Mistura & $\begin{array}{l}\text { Hidróxido } \\
\text { de Cálcio } \\
\text { (g) }\end{array}$ & $\begin{array}{l}\text { Adições } \\
\text { (g) }\end{array}$ & $\begin{array}{l}\text { Areia } \\
(g)\end{array}$ & $\begin{array}{l}\text { Água } \\
(g)\end{array}$ & $\begin{array}{l}\text { Consistência } \\
\text { média (mm) }\end{array}$ & $\begin{array}{c}\text { Relação } \\
\text { água/ } \\
\text { aglomerante }\end{array}$ & $\begin{array}{c}\text { Resistência } \\
\text { à compressão } \\
\text { (Mpa) }\end{array}$ & $\begin{array}{l}\text { IAC } \\
\left(\frac{\circ}{0}\right)\end{array}$ \\
\hline CBCAN & \multirow{5}{*}{208,00} & 494,54 & \multirow{5}{*}{1872} & 500,94 & 220 & 0,713 & 0,30 & 4,99 \\
\hline CBCAN3 & & 494,54 & & 410,63 & 229 & 0,584 & 1,31 & 21,78 \\
\hline CBCAN4 & & 494,54 & & 406,31 & 229 & 0,578 & 1,74 & 29,00 \\
\hline CBCAN5 & & 494,54 & & 404,23 & 228 & 0,575 & 2,76 & 45,92 \\
\hline MTC & & 485,62 & & 635,35 & 220 & 0,916 & 13,28 & 221,28 \\
\hline
\end{tabular}

Tabela 3: Composição das argamassas obtidas para a confecção de 6 corpos-de-prova

\section{Conclusão}

De modo geral, a cinza do bagaço de cana-de-açúcar (CBCA) utilizada neste trabalho não apresentou índices de atividade com cal (IAC) (NBR 5751 [20]) que permitam classificar o material como pozolânico (NBR 12653 [1]) . No entanto, observou-se um aumento do IAC com a medida que se aumentava o grau de moagem, indicando uma relação direta ente o IAC e a área específica da CBCA. Portanto, é possível que, em pesquisas futuras, este material com o tratamento adequado contribua para que seja alcançado a reatividade necessária para que ele possa ser classificado como pozolana. As principais conclusões deste estudo são:

- Nenhuma das misturas estudadas com a cinza atingiu o IAC mínimo de 6Mpa exigido pela NBR 12653;

- Quando analisado o efeito da moagem, observouse um aumento do potencial pozolânico mensurado pelo IAC e que este aumento está diretamente relacionado com um aumento do grau de moagem. Este comportamento era esperado, pois é consensual na bibliografia levantada que a atividade pozolânica do material está ligada à sua superfície específica;

Sustentavelmente, também é interessante o uso de CBCA, visando a diminuição do impacto no meio ambiente.

\section{Referências}

[1] ASSOCIAÇÃO BRASILEIRA DE NORMAS TÉCNICAS. NBR 12653: Materiais pozolânicos - Especificação. Rio de Janeiro, 2014.

[2] VIEIRA, A. A. P. Estudo do aproveitamento de resíduos de cerâmica vermelha como substituição pozolânica em argamassas e concretos. Dissertação (mestrado) - João Pessoa: UFPB, 2005. $107 \mathrm{p}$.
[3] MORAES, M. J. B. ; SILVA, L. H. P. ; PEREIRA, A. M. ; AKASAKI, J. L. ; PAYÁ, J. ; MONZÓ, J. M. Análise da cinza da cana-deaçúcar e da cinza de casca de arroz como adição mineral em argamassas. In: $57^{\circ}$ Congresso Brasileiro do Concreto, 2015, Bonito. Anais do $57^{\circ}$ Congresso Brasileiro de Concreto, 2015.

[4] ÚNICA - União da Indústria de Cana-de-Açúcar (2015) Disponível na internet: $<$ http://www.unica.com.br>. Acesso em novembro de 2015

[5] COSTA, W. L. S. ; BOCCHI, M. L. M. Aplicações do bagaço da cana de açúcar na atualidade. Revista Ciência e Tecnologia vol. 4. N.1 2012.

[6] NUNES, I. H. S. ; VANDERLEI, D. R. ; SECCHI, M. ; ABE, M.A.P. Estudo das características físicas e químicas da cinza do bagaço de cana-de-açúcar para uso na construção. Revista Tecnológica, v. 17, p. 39-48, 2008.

[7] ROMERO, T. Bagaço na construção civil. Agência de Notícias da Fundação de Amparo à Pesquisa do Estado de São Paulo (2007). Disponível na internet: $<$ http://agencia.fapesp.br/bagaco_na__construcao_civil/7211/>. Acesso em novemb̄o de 2015.

[8] BORLINI, M. C. ; MENDONÇA, J. L. C. C. ; PINATTI, D. G. ; CONTE, R. A. ; VIEIRA, C. M. F. ; MONTEIRO, S. N. Cerâmica com cinza de bagaço de cana de açúcar: avaliação da influência da cinza e da sua granulometria nas propriedades físicas e mecânicas.. In: Congresso Brasileiro de Engenharia e Ciência dos Materiais - CBECIMAT, 17, 2006, Foz do Iguaçu. Anais do 17 CBECIMAT, 2006. p. 2033-2041.

[9] LIMA, S. A. ; SALES, A.; MORETTI, J. P. ; SANTOS, T. J. Análise de argamassas confeccionadas com a cinza do bagaço da cana-de-açúcar em substituição ao agregado miúdo. Revista Tecnológica, Edição Especial ENTECA 2009, p. 
87-97, 2009.

[10] LIMA, J. S. ; AMARAL, M. L. ; ARAUJO, F. W. C. ; MIRANDA, L. F. R. ; MELO NETO, A. A . Emprego da cinza do bagaço de cana-deaçúcar (in natura) como adição ao cimento Portland em argamassas. In: $54^{\circ}$ Congresso Brasileiro do Concreto, 2012, Maceió. Anais do $54^{\circ}$ Congresso Brasileiro do Concreto, 2012.

[11] MAGALHÃES, R. S. Desenvolvimento de Material Vitro-Cerâmico através de Vitrificação e Cristalização Controlada de Cinza de Bagaço de Cana: Sistema (SiO2-CaO-Na2O). In: XXI Congresso de Iniciação Científica da Unesp, 2009, São José do Rio Preto.

[12] TEIXEIRA, D. E. ; SANTANA, M. A. E. ; COSTA, A. F. Aglomerados de bagaço de canade-açúcar: resistência natural ao ataque de fungos apodrecedores. Scientia Forestalis (IPEF). , v.52, p.29 - 34, 1997.

[13] PEREIRA, A. M. ; TASHIMA, M. M. ; MELGES, J. L. P. ; AKASAKI, J. L. ; PAYÁ, J. ; SORIANO, L. O uso da cinza de bagaço de cana-de-açúcar na produção de matrizes ativadas alcalinamente. In: $57^{\circ}$ Congresso Brasileiro do Concreto, 2015, Bonito. Anais do $57^{\circ}$ Congresso Brasileiro de Concreto, 2015.

[14] SILVA, D. L. ; ANDRADE, G. P. ; MONTEIRO, E. C. B. Avaliação do efeito da substituição parcial do cimento Portland pela cinza da queima do bagaço da cana de açúcar na resistência à compressão do concreto. In: $57^{\circ}$ Congresso Brasileiro do Concreto, 2015, Bonito. Anais do $57^{\circ}$ Congresso Brasileiro de Concreto, 2015.

[15] CALDAS, A. ; MELO NETO, A. A. ; PIRES SOBRINHO, C. W. A. ; JOHN, V. M. . O uso de cinzas residuais para produção de novos materiais e componentes construtivos. In: II Congresso Internacional de Tecnologia e Gestão da Qualidade na Construção Civil, 2000, Recife-PE. II Congresso Internacional de Tecnologia e Gestão da Qualidade na Construção Civil, 2000.

[16] PAULA, M. O. Potencial da cinza de bagaço de cana-de-açúcar como material de substituição parcial do cimento Portland. Dissertação (mestrado) - Viçosa: UFV, 2006. 77 p.

[17] CORDEIRO, G. C., TOLEDO FILHO, R. D., FAIRBAIRN, E. M. R., Influência da substituição parcial de cimento por cinza ultrafina da casca de arroz com elevado teor de carbono nas propriedades do concreto. Ambiente Construído, v. 9, p. 99-107, out.-dez. 2009.
[18] AMARAL, M. L. ; LIMA, J. S. ; ARAUJO, F. W. C. ; MIRANDA, L. F. R. MELO NETO, A. A. Análise da atividade pozolânica da cinza do bagaço de cana-de-açúcar submetida a tratamento térmico. In: XIV ENTAC - Encontro Nacional de Tecnologia do Ambiente Construído, 2012, Juiz de Fora. XIV ENTAC - Encontro Nacional de Tecnologia do Ambiente Construído. Juiz de Fora, 2012. p. 3674-3678.

[19] ZARDO, A. M.; BEZERRA, E. M.; MARTELLO, L. S.; SAVASTANO Jr., H. Utilização da cinza de bagaço cana-de-açúcar como "filler" em compostos de fibrocimento. In: I Conferência Latino-americana de Construção Sustentável/x Encontro Nacional de Tecnologia do Ambiente Construído, 2004, São Paulo. Anais. São Paulo: Entac, 2004. CD-ROM.

[20] ASSOCIAÇÃO BRASILEIRA DE NORMAS TÉCNICAS. NBR 5751: Materiais pozolânicos Determinação da atividade pozolânica com cal aos sete dias. Rio de Janeiro, 2015.

[21] ASSOCIAÇÃO BRASILEIRA DE NORMAS TÉCNICAS. NBR NM 76: Cimento Portland Determinação da finura pelo método de permeabilidade ao ar (Método de Blaine). Rio de Janeiro, 1998.

[22] ASSOCIAÇÃO BRASILEIRA DE NORMAS TÉCNICAS. NBR 7215: Cimento Portland Determinação da resistência à compressão. Rio de Janeiro, 1996.

[23] ASSOCIAÇÃO BRASILEIRA DE NORMAS TÉCNICAS. NBR NM 23: Cimento Portland e outros materiais em pó - Determinação de massa específica. Rio de Janeiro, 2001.

[24] ASSOCIAÇÃO BRASILEIRA DE NORMAS TÉCNICAS. NBR 7214: Areia normal para ensaio de cimento - Especificação. Rio de Janeiro, 2012. 